\title{
The kinetics of hot-pressing for undoped and donor-doped $\mathrm{BaTiO}_{3}$ ceramics
}

\author{
L. A. XUE* Y. CHEN", E. GILBART, R. J.BROOK ${ }^{\S}$ \\ Department of Ceramics and ${ }^{\ddagger}$ Department of Civil Engineering, The University of Leeds, \\ Leeds LS2 9JT, UK
}

The kinetics of hot-pressing for undoped and donor-doped $\mathrm{BaTiO}_{3}$ of high purity have been studied at $1050^{\circ} \mathrm{C}$ and at 2.3 to $27.6 \mathrm{MPa}$ in an oxidizing atmosphere. The stress exponent and grain size exponent of the densification rate are indicative of control of densification by a grain boundary diffusion mechanism. The activation enthalpy $\left(\sim 400 \mathrm{~kJ} \mathrm{~mol}^{-1}\right)$ for the densification process has been measured over the range of 1050 to $1200^{\circ} \mathrm{C}$. No significant influence of the donor is observed on the densification of $\mathrm{BaTiO}_{3}$ until the late stages of sintering.

\section{Introduction}

Barium titanate has been hot-pressed by many investigators [1-10], the ultimate objective having usually been to achieve high density with small grain size so as to obtain a high dielectric constant or a high dielectric breakdown strength. As an example, Brandmayr et al. [3] hot-pressed high-purity $\mathrm{BaTiO}_{3}$ of $0.05 \mu \mathrm{m}$ starting particle size at a temperature as low as $820^{\circ} \mathrm{C}$ and at a pressure of $207 \mathrm{MPa}$ for $0.5 \mathrm{~h}$; they achieved a relative density of $98 \%$ with a final grain size of $0.05 \mu \mathrm{m}$ and a maximum room-temperature dielectric constant of 5200 .

It is known that $\mathrm{BaTiO}_{3}$ tends to show abnormal grain growth during conventional sintering $[11,12]$. The success of the hot-pressing technique in realizing high densities while retaining fine grain sizes in $\mathrm{BaTiO}_{3}$ implies an enhanced ratio of densification rate to coarsening, thus leading to a smaller pore size and a higher pore mobility at a given density, and therefore reducing the chances of pore-boundary separation. The lower temperature utilized in hot-pressing may also be a benefit in this matter, owing to the reduced opportunity for liquid phase formation.

The hot-pressing kinetics of $\mathrm{BaTiO}_{3}$ have not been much considered in the literature. Employing a graphite die and punch, Mostaghaci [8] studied the kinetics of hot-pressing of $\mathrm{BaTiO}_{3}$ at $1350^{\circ} \mathrm{C}$ and at 5 to $25 \mathrm{MPa}$. The results were evaluated by analogy with the power-law creep relationship, employing a general creep equation of the form [14]

$$
\dot{\varepsilon}=\frac{A D g b}{k T}\left(\frac{b}{G}\right)^{m}\left(\frac{\sigma}{g}\right)^{n}
$$

for the deformation rate (or the densification rate), where $A$ is a dimensionless constant, $D$ a diffusion coefficient having an exponential temperature dependence, $g$ the shear modulus, $b$ the magnitude of the Burgers vector, $G$ the grain size, $\sigma$ the applied stress, and where $m$ and $n$ are grain size and stress exponents, respectively. In principle, knowledge of the pressure and grain size dependence of the hot-pressing rate allows a determination of the dominant densification mechanism [14].

The attainment of a stress exponent $n$ of about unity in Mostaghaci's study indicated that diffusional creep processes were the dominant mechanism for densification under the conditions used, while distinction between lattice and grain boundary diffusion required further investigation. The activation energy of the densification process(es) was also determined in the temperature range of 1280 to $1410^{\circ} \mathrm{C}$ and was found to have a value of $\sim 506 \mathrm{~kJ} \mathrm{~mol}^{-1}$. In a later study, the grain size dependence of the densification rate was estimated by Mostaghaci and Brook [15]. A value of 1.13 for the grain size exponent $m$ in Equation 1 was obtained for samples hot-pressed at $1300^{\circ} \mathrm{C}$ and at 15.1 MPa for different times from 100 to $800 \mathrm{sec}$. This suggested the possibility of process control by the viscous flow of a boundary liquid film, an interpretation consistent with the presence of a relatively high level of impurity $(\sim 0.5 \%)$ in the technical-grade powder used. However, the measurements were made at very different densities (ranging between $\sim 72 \%$ and $\sim 93 \%$ ). The reducing atmosphere may also have affected the kinetic observations.

The primary purpose of the present work has been to clarify the aforementioned doubts by employing high purity (impurities $<0.1 \%$ ), well characterized powder and by adopting an oxidizing atmosphere during the hot-pressing. The influence of donor dopants on the densification of $\mathrm{BaTiO}_{3}$ has also been studied because of their interesting ability to inhibit grain growth during the sintering of this material [11].

\section{Experimental procedure}

\subsection{Powder preparation and doping procedure}

Both a commercial high-purity $\mathrm{BaTiO}_{3}$ (HPB 99.9\%,

* Present address: Department of Materials Science and Engineering, University of Michigan, Ann Arbor, Michigan 48109, USA.

$\S$ Present address: Max Planck Institut für Metallforschung, 7000 Stuttgart 80 , West Germany. 
TAM Ceramics Inc., Lot. 708) and a chemically synthesized $\mathrm{BaTiO}_{3}$ powder, prepared using a complex peroxide route [16], were employed as the starting materials; they had mean particle sizes of $\sim 0.4$ and $\sim 0.04 \mu \mathrm{m}$, respectively, as calculated from their specific surface areas as determined by the BET method. Tantalum and lanthanum were selected as the donor dopants. The chemical reagents involved during the powder preparation were all of high purity $(>99.9 \%)$.

The A/B ratio of the chemically synthesized powder (CS) was unity. Here A and B represent the total of all species occupying the 12-coordination A sites (barium sites) and the 6-coordination B sites (titanium sites), respectively. Tantalum was introduced as $\mathrm{TaCl}_{5}$ ethanol solution into the precursor solution during the coprecipitation process. The $\mathrm{A} / \mathrm{B}$ ratio of the asreceived HPB powder was 0.993 , which was adjusted to 0.994 by addition of barium acetate solution. Donors were added in the form of either $\mathrm{TaCl}_{5}$ ethanol solution or $\mathrm{La}\left(\mathrm{NO}_{3}\right)_{3}$ aqueous solution to an ethanol suspension of HPB powder which had been ultrasonically agitated; they were then precipitated using ammonia solution, the suspension being continually stirred with a magnetic stirrer. Drying was achieved by a combination of infrared heating above and a hotplate below. The dried powders were ground in an agate mortar and calcined at a temperature of $1100^{\circ} \mathrm{C}$ for $5 \mathrm{~h}$.

\subsection{Powder classification}

In order to obtain information on the grain size dependence of the densification rate, the HPB powder (after having been calcined at $1150^{\circ} \mathrm{C}$ for $10 \mathrm{~h}$ and wet-milled with propan-2-ol for $5 \mathrm{~min}$ in a micronizer charged with small zirconia cylinders) was classified into four narrower-distribution powders of different sizes by way of sedimentation [17]. The mean particle sizes as measured by the BET method were $0.39,0.48$, 0.56 and $0.80 \mu \mathrm{m}$ for the fractions denoted CL1, CL2, CL3 and CL4, respectively.

\subsection{Hot-pressed procedure}

The hot-pressing apparatus used was an upgraded version of the equipment described previously [18]. Specimens were hot-pressed in a $1.45 \mathrm{~cm}$ bore zirconia die using zirconia punch and spacers to apply the pressure. Graphite was used as the suscepter material which was sealed inside an alumina tube and an alumina furnace case to prevent it from oxidizing. $1.8 \mathrm{~g}$ of $\mathrm{BaTiO}_{3}$ powder were used for each hot-pressing experiment. A pressure slightly greater than that of the intended hot-pressing was applied to the cold compact, using a gas-ballasted hydraulic accumulator, and released. The system was then induction-heated. When the hot-pressing temperature had been reached, the pressure was reapplied and stabilized within $1 \mathrm{sec}$. Throughout the experiment, the pressure and temperature were maintained to within $\pm 0.5 \mathrm{MPa}$ and $\pm 5^{\circ} \mathrm{C}$, respectively. Shrinkage data from the samples were automatically collected by an Apple microcomputer through a linear variable displacement transducer.

The final density and thickness of the hot-pressed discs were measured to allow processing of the acquired data in terms of the time dependence of the sample density.

\section{Results and discussion}

For hot-pressing, Equation 1 can be rewritten (neglecting the small influence of the linear factor $1 / T$ ) as

$$
\frac{\mathrm{d} \varrho}{\mathrm{d} t}=\frac{A^{\prime} D_{0} \exp (-Q / R T) P^{n}}{G^{m} \varrho^{n-1}}
$$

where $\varrho, P$ and $Q$ are the density, applied pressure and activation enthalpy, respectively. The parameters $m$, $n$, and $Q$ can then be calculated from the dependence of the densification rate on each of the variables $P, G$ and $T$ separately [19].

\subsection{Pressure dependence of densification rate [20]}

In the present study, attention was particularly given to the influence of the donor dopants on the densification. Fig. la shows some typical density-time curves obtained at $1050^{\circ} \mathrm{C}$ for the hot-pressing of 0.5 at $\%$ tantalum-doped $\mathrm{BaTiO}_{3}(\mathrm{CS})$ at pressures between 2.3 and $27.6 \mathrm{MPa}$. The relatively low hot-pressing temperature was adopted to avoid any presence of liquid boundary phases which would be expected at temperatures around $1300^{\circ} \mathrm{C}$, the established eutectic temperature in this system being $1312^{\circ} \mathrm{C}$ [21].

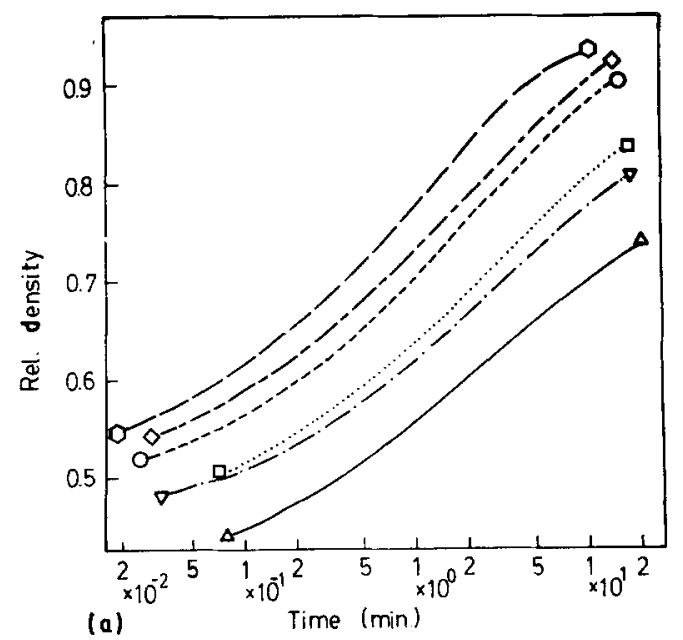

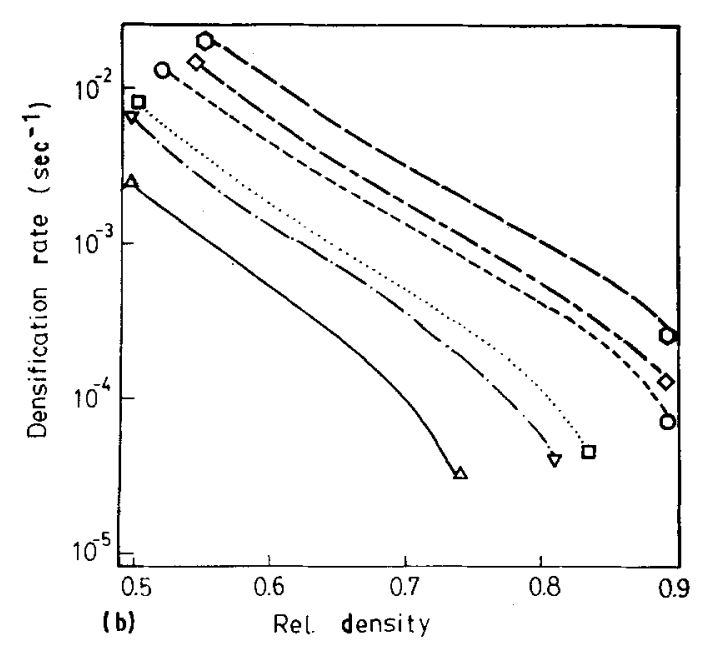

Figure 1 (a) Density-time plot and (b) densification rate-density plot for $\mathrm{BaTiO}_{3}$ doped with $0.5 \mathrm{at} \% \mathrm{Ta}$, hot-pressed at $1050^{\circ} \mathrm{C}$ and at various pressures: $(\Delta, \longrightarrow) 2.3 \mathrm{MPa} ;(\nabla,-\cdot) 4.8 \mathrm{MPa}(\square, \cdots) 7.0 \mathrm{MPa} ;(\mathrm{O},--) 14.1 \mathrm{MPa} ;(\diamond,--) 19.5 \mathrm{Mpa} ;(\bigcirc,--) 27.6 \mathrm{MPa}$. 


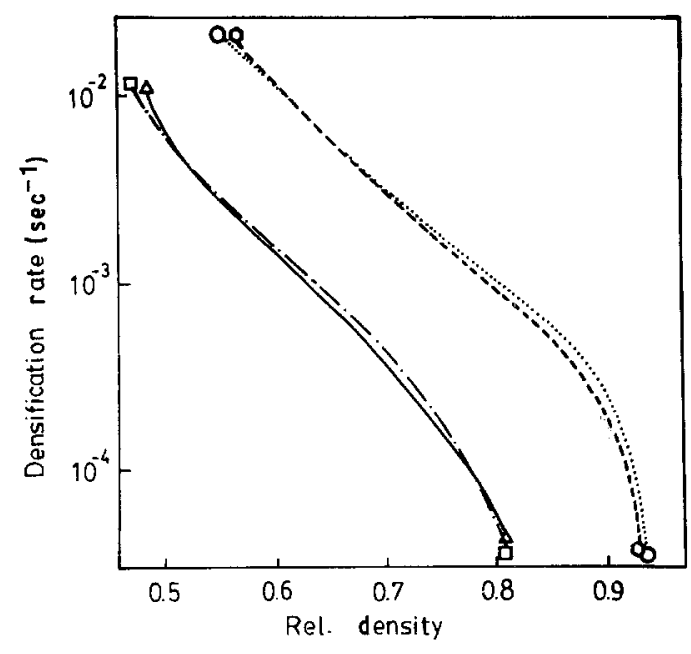

Figure 2 Densification rate against density for undoped and doped $\mathrm{BaTiO}_{3}$ (CS) hot-pressed at $1050^{\circ} \mathrm{C}$ at two different pressures: $(\square,-\cdot)$ undoped, $4.9 \mathrm{MPa} ;(\triangle, \longrightarrow) 0.5 \mathrm{at} \% \mathrm{Ta}, 4.8 \mathrm{MPa}$; $(\mathrm{O},--)$ undoped, 27.2 $\mathrm{MPa} ;(\mathrm{O}, \cdots) 0.5$ at $\% \mathrm{Ta}, 27.6 \mathrm{MPa}$

As can be seen from the curves, the fine particle size made the densification of the chemically derived powder very fast even at relatively low temperature, a density of $90 \%$ of the theoretical being reached in $40 \mathrm{sec}$ at $27.6 \mathrm{MPa}$. The corresponding densification rate-density curves are plotted in Fig. 1b. Almost identical results were found for undoped $\mathrm{BaTiO}_{3}(\mathrm{CS})$ and for compositions using other donor contents. No obvious influence of dopants was observed, as is indicated in Fig. 2, where densification rate against density curves are shown for 0.5 at $\%$ tantalum-doped and for undoped $\mathrm{BaTiO}_{3}(\mathrm{CS})$. It is seen that no appreciable effect of the dopant occurs until very late in the sintering. This will be discussed later.

At fixed $T$ and $\varrho$, with the same starting powder, Equation 2 reduces to

$$
\log (\mathrm{d} \varrho / \mathrm{d} t)=\text { constant }+n \log P
$$

Hence $n$ can be readily obtained from the slope of the line relating the logarithm of the densification rate to the logarithm of the applied pressure. This is given in Fig. 3, where data from Fig. $1 \mathrm{~b}$ are plotted with least-squares fit. The resultant values of the slopes are shown for different relative densities, the largest

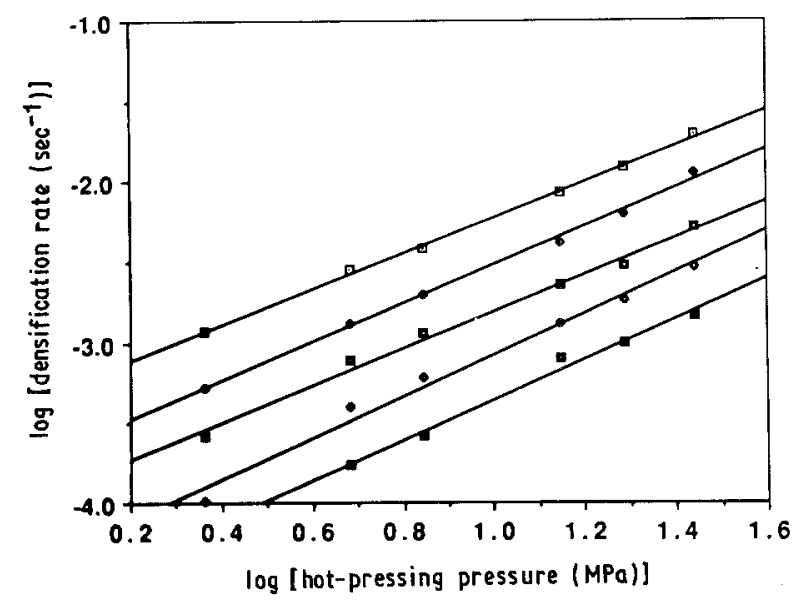

Figure 3 Pressure dependence of the densification rate in $\mathrm{BaTiO}_{3}$ (CS) doped with 0.5 at $\% \mathrm{Ta}$, hot-pressed at $1050^{\circ} \mathrm{C}$ : (অ) relative density $55 \%$, slope 1.11 ; ( $60 \%$, slope 1.16 ; (ㅁ) $65 \%$, slope 1.14 ;

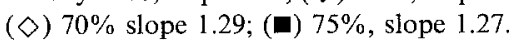

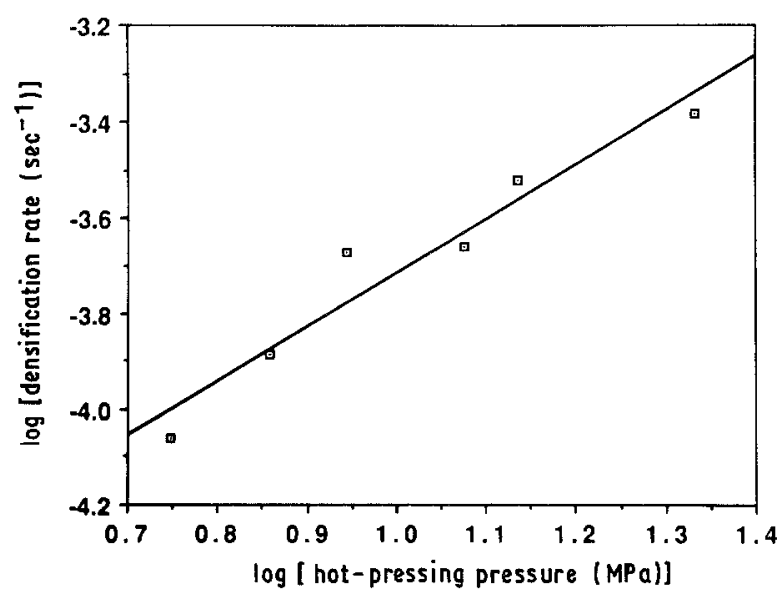

Figure 4 Pressure dependence of the densification rate for undoped $\mathrm{BaTiO}_{3}$ (CL2). Slope $=1.09$.

standard deviation being 0.22 . Figures of about unity for $n$ are therefore obtained, indicating that a diffusion mechanism is responsible for the densification of the material under the conditions cited. The $\mathrm{BaTiO}_{3} \mathrm{HPB}$ yields a similar value of $n$. For example, a hot-pressing study conducted on classified $\mathrm{BaTiO}_{3} \mathrm{HPB}$ powder (CL2) in the pressure range of 5.6 to $21.6 \mathrm{MPa}$ results in a value for $n$ of $1.09 \pm 0.23$ as shown in Fig. 4 .

Typical microstructures of the hot-pressed $\mathrm{BaTiO}_{3}$ HPB samples can be seen in Fig. 5, which shows microfractographs of (a) undoped and (b) $0.6 \mathrm{at} \%$ lanthanum-doped $\mathrm{BaTiO}_{3}$ hot-pressed at $1130^{\circ} \mathrm{C}$ at $20 \mathrm{MPa}$ for $60 \mathrm{~min}$, with relative densities of 98.6 and $99.0 \%$, respectively. The fine microstructures with submicrometre grains are indicative of the absence of abnormal grain growth. Actually, relatively little normal grain growth is observed. This again demonstrates the value of hot-pressing as a mean of achieving high densities while retaining small grain sizes.

The results for the stress exponent $n$ agree with those obtained by Mostaghaci [8] and therefore support the view that a diffusional creep or a grain boundary sliding mechanism is likely to be responsible for the densification of $\mathrm{BaTiO}_{3}$.

\subsection{Grain size dependence of densification rate}

At constant pressure, temperature and composition, Equation 2 becomes

$$
\log (\mathrm{d} \varrho / \mathrm{d} t)=\text { constant }-m \log G
$$

Four different particle-sized $\mathrm{BaTiO}_{3}$ powders (CL1, CL2, CL3 and CL4) classified from the HPB were employed in this part of the study. The hot-pressing of these powders was carried out at $1050^{\circ} \mathrm{C}$ and $20 \mathrm{MPa}$. The results are plotted in Fig. 6, which shows (a) density-time and (b) densification rate-density diagrams for these samples.

The microstructures of the specimens made from these different classes of powders but having the same relative density ( $78 \pm 1 \%$ ) were examined with SEM. These specimens were quenched from the hot-pressing temperature after they had been hot-pressed at $1050^{\circ} \mathrm{C}$ and $20 \mathrm{MPa}$ for the required given time. The measured grain sizes were $0.41,0.52,0.60$ and $0.91 \mu \mathrm{m}$ 

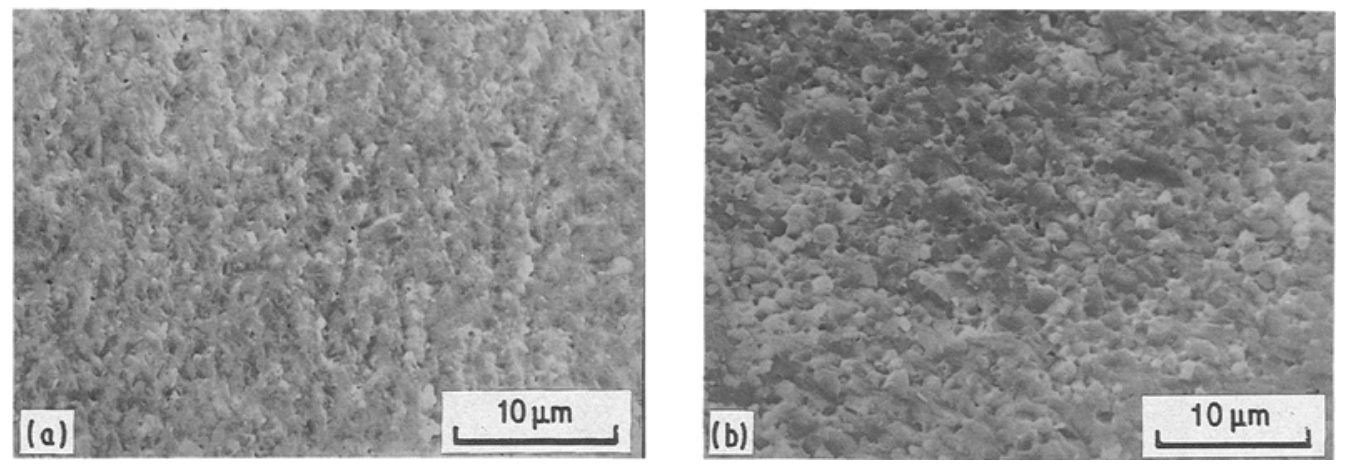

Figure 5 Microfractographs of $\mathrm{BaTiO}_{3} \mathrm{HPB}$ (a) undoped and (b) doped with 0.6 at \% Ta, hot-pressed at $1130^{\circ} \mathrm{C}$ and $20 \mathrm{MPa}$ for $60 \mathrm{~min}$.

for specimens made from the CL1, CL2, CL3 and CL4 powders, respectively. Employing these data, the densification rate can be shown as a function of grain size as in Fig. 7, which gives a slope of $-3.2 \pm 0.6$. This $m$ value of close to 3 favours grain boundary diffusion as the controlling mechanism for the densification process $[13,14]$. This finding is different from the $m$ value of 1.13 obtained by Mostaghaci and Brook [15] which suggested the possibility of process control by viscous flow of a boundary liquid film. That interpretation may have been justified for the conditions under which the experiments were done, i.e., relatively high hot-pressing temperature $\left(1300^{\circ} \mathrm{C}\right)$ and relatively low purity powders $(\sim 0.5 \%$ impurities $)$. In the present study, however, the operation of such a mechanism based on boundary liquid films is very unlikely, owing to the low hot-pressing temperature and the relatively high purity powders $(<0.1 \%$ impurities $)$ employed. The independence of the densification rate from the presence of donor dopants during sintering [17] and hot-pressing, at least during the initial and intermediate stages, also argues against lattice diffusion as the controlling process.

\subsection{Temperature dependence of densification rate}

Typical isobaric density-time curves for the hotpressing of $0.3 \mathrm{at} \%$ tantalum-doped $\mathrm{BaTiO}_{3}(\mathrm{CS})$ are given in Fig. 8. The samples were hot-pressed at tem- peratures between 1050 and $1200^{\circ} \mathrm{C}$ using a pressure of $15 \mathrm{MPa}$.

The values of the determined activation enthalpy $Q$ at each relative density (Fig. 9) are lower than that of Mostaghaci [8], namely $506 \mathrm{~kJ} \mathrm{~mol}^{-1}$ over the temperature range of 1280 to $1400^{\circ} \mathrm{C}$ at $10 \mathrm{MPa}$. Since the donor dopants in the composition range studied do not have any significant influence on the densification rate of this material until late in sintering (up to $90 \%$ of the theoretical, refer to the discussion in the following section), the lower value obtained cannot be attributed to the dopant effect. This has been confirmed in results from the hot-pressing of undoped $\mathrm{BaTiO}_{3}(\mathrm{CS})$ under the same conditions, a similar value of $392 \pm 27 \mathrm{~kJ} \mathrm{~mol}^{-1}$ being attained.

This level of $Q$ is to be compared with the $Q$ value of $372 \mathrm{~kJ} \mathrm{~mol}^{-1}$ reported in the temperature range 884 to $1180^{\circ} \mathrm{C}$ for barium self-diffusion in polycrystalline $\mathrm{BaTiO}_{3}$ [22], which may itself represent a grain boundary coefficient.

Other experiments on the activation enthalpy of $\mathrm{BaTiO}_{3}$ in the literature are all limited to investigations on initial shrinkage studies. Data from an isothermal shrinkage study in the temperature range 700 to $1000^{\circ} \mathrm{C}$ give a $Q$ value of $468 \mathrm{~kJ} \mathrm{~mol}^{-1}$ [23], while a non-isothermal method with heating at a rate of $5^{\circ} \mathrm{C} \mathrm{min}^{-1}$ up to $1350^{\circ} \mathrm{C}$ yields a $Q$ of $500 \mathrm{~kJ} \mathrm{~mol}^{-1}$ [24].

The different powders and the different tempera-
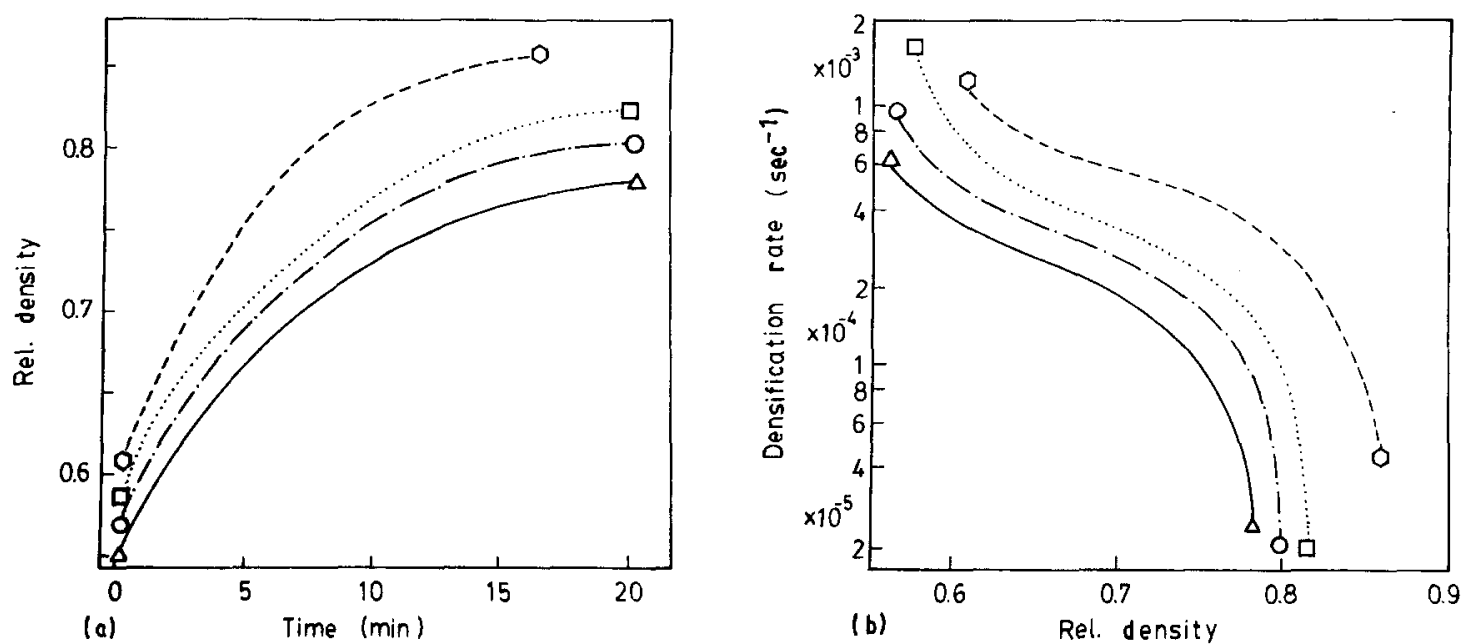

Figure 6 The influence of grain size on the densification of classified $\mathrm{BaTiO}_{3}$; (a) density against time, (b) densification rate against density. $(\mathrm{O},-\cdots) \mathrm{CL} 1 ;(\square, \cdots) \mathrm{CL} 2 ;(\mathrm{O},-\cdot) \mathrm{CL} 3 ;(\Delta,-) \mathrm{CL} 4$. 


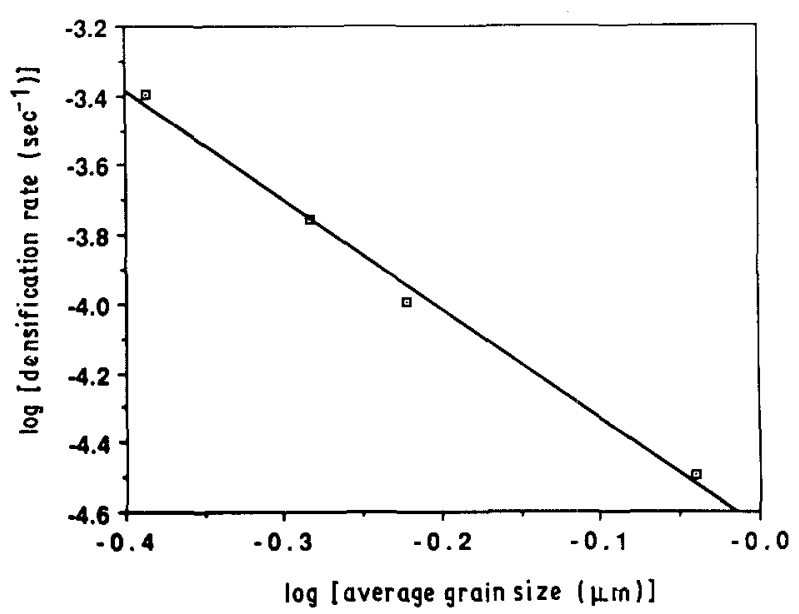

Figure 7 Dependence of densification rate on grain size for classified $\mathrm{BaTiO}_{3}$ samples hot-pressed at $1050^{\circ} \mathrm{C}$ and $20 \mathrm{MPa}$ (at relative density $78 \pm 1 \%$ ). Slope $=-3.20$.

tures involved in these studies make comparison of activation energies unrewarding. As an example of the problem, Enomoto and Yamaji found, in the same study [24], a $Q$ value of $290 \mathrm{~kJ} \mathrm{~mol}^{-1}$ for samples made of fine powder $(0.05 \mu \mathrm{m})$, and the value $500 \mathrm{~kJ} \mathrm{~mol}^{-1}$ quoted above for a less fine powder $(0.3 \mu \mathrm{m})$.

This noticeable dependence of $Q$ on powder particle size may stem from the affect of variation in the degree and quality of agglomeration in the powders. Agglomeration modifies strongly the sintering behaviour of ceramics $[25,26]$. Under a given external applied pressure the breakdown of hard agglomerates may itself be temperature-dependent so that a heavily agglomerated powder may exhibit a higher apparent $Q$ value. The influence of the temperature range may also arise from the interference of a liquid boundary phase which is expected to form at around the eutectic point of $1312^{\circ} \mathrm{C}$ [21]. The participation of such a liquid phase during sintering and hot-pressing can lead to a switch-over between controlling mechanisms as already expected on the basis of the comparison between the $m$ values of the present study and the earlier work [15].

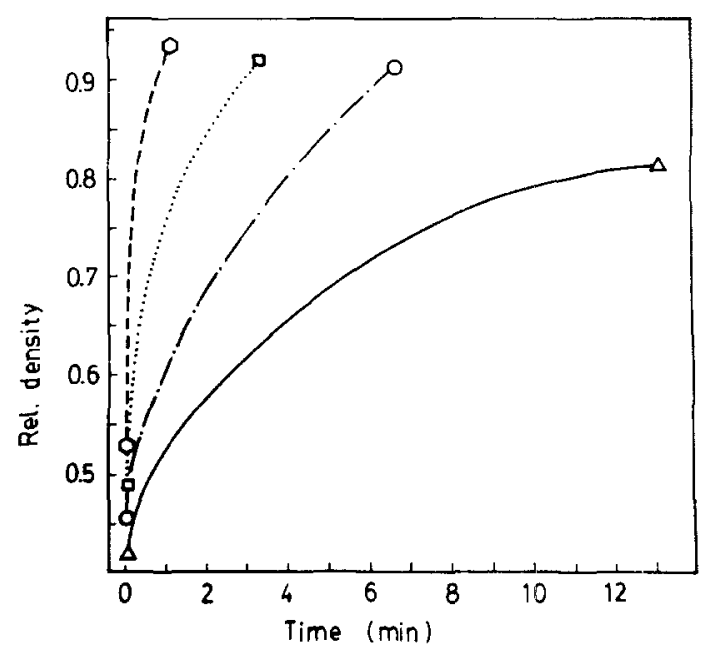

Figure 8 Density against time for $\mathrm{BaTiO}_{3}(\mathrm{CS})$, doped with 0.3 at $\%$ $\mathrm{Ta}$, hot-pressed at $15 \mathrm{MPa}$ and at various temperatures: $(\triangle, \longrightarrow)$ $1050^{\circ} \mathrm{C} ;(\mathrm{O},-\rightarrow) 1100^{\circ} \mathrm{C} ;(\square, \cdots) 1150^{\circ} \mathrm{C} ;(0,--) 1200^{\circ} \mathrm{C}$.

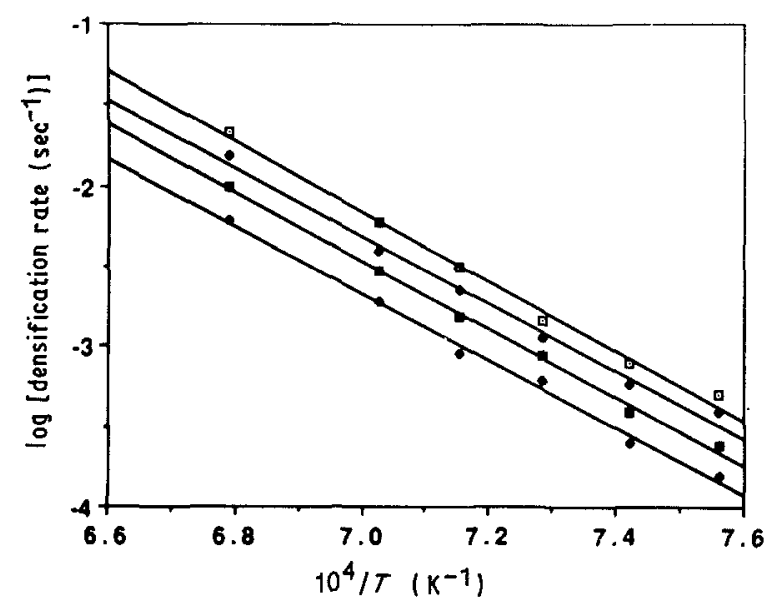

Figure 9 Arrhenius plot for densification rate during the hotpressing of $\mathrm{BaTiO}_{3}$ (CS) doped with 0.3 at \% Ta, at temperature and pressure $15 \mathrm{MPa}$. Values at four different relative densities are drawn: (๑) $65 \%, Q=417 \mathrm{~kJ} \mathrm{~mol}^{-1}$; (•) $70 \%, Q=403 \mathrm{~kJ} \mathrm{~mol}^{-1}$; (ㅁ) $75 \%, Q=408 \mathrm{~kJ} \mathrm{~mol}^{-1} ;(\diamond) 80 \%, Q=400 \mathrm{~kJ} \mathrm{~mol}^{-1}$.

\subsection{Influence of donor content on densification rate}

\subsubsection{Initial and intermediate sintering stages}

Fig. 10 shows densification rate-density data for various doping levels of lanthanum-doped $\mathrm{BaTiO}_{3}$ HPB hot-pressed at $1150^{\circ} \mathrm{C}$ and $20 \mathrm{MPa}$. As can be clearly seen, these samples give similar curves. No regularity is observed in the influence of the dopant concentration on the densification rate until the very late stages of sintering. The same is found in tantalumdoped $\mathrm{BaTiO}_{3}$. These results are consistent with those obtained in the sintering dilatometer study of this material [17].

\subsubsection{Final sintering stage}

It can be seen from Fig. 10 that in the late stage of sintering, the donor tends to promote densification. A densification rate against dopant content diagram is plotted on a $\log -\log$ scale in Fig. 11, using the observed densification rate at a relative density of $94 \%$. This yields a slope of $0.48 \pm 0.09$, indicating some donor-dependence of the densification rate at

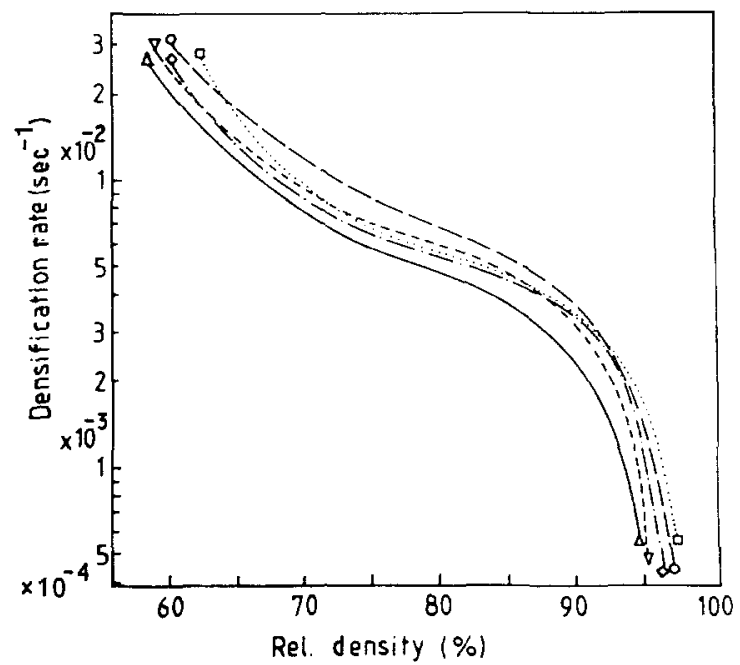

Figure 10 Densification rate-density plot for various doping levels of lanthanum-doped $\mathrm{BaTiO}_{3} \mathrm{HPB}$ hot-pressed at $1150^{\circ} \mathrm{C}$ and $20 \mathrm{MPa}$. Lanthanum concentration $($ at $\%):(\triangle,-) 0.1 ;(\nabla,---)$ $0.2 ;(\diamond,-\cdot-) 0.4 ;(0,--) 0.6 ;(\square, \cdots) 0.8$. 


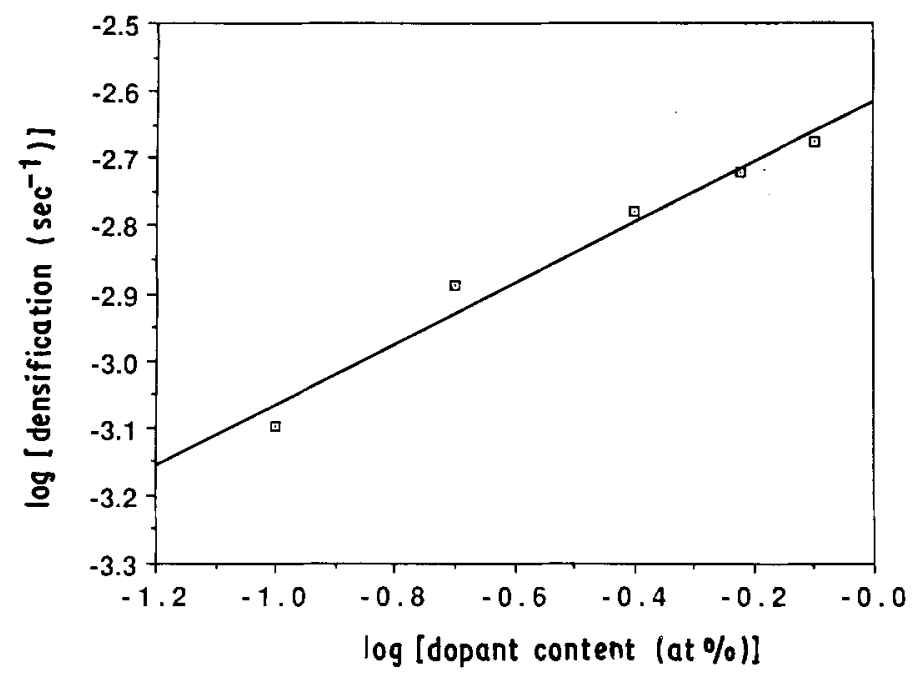

Figure $1 /$ Dependence of densification rate in the late stage of sintering (at relative density $94 \%$ ) on dopant content for lanthanum-doped $\mathrm{BaTjO}_{3} \mathrm{HPB}$ hot-pressed at $1150^{\circ} \mathrm{C}$ and $20 \mathrm{MPa}$ (relative density $94 \%$ ). Slope $=0.48$.

this stage. Such a slope would be expected for control by titanium vacancies under circumstances where bulk neutrality in the system is achieved by $[\dot{\mathrm{D}}]=4\left[\mathrm{~V}_{\mathrm{Ti}}^{\prime \prime \prime}\right]$. However, the short density span over which the effect is found and the complications introduced by overlapping mechanisms (the grain boundary diffusion control of the intermediate density range) make any specific defect interpretation unreliable. The independence of the densification rate from the donor concentration in the earlier sintering stages is consistent with the results of the kinetics study. Since grain boundary diffusion is believed to be the controlling mechanism for densification, the bulk effect of the donor [17] is not expected to have an influence.

\section{Conclusion}

The stress exponent $n$ found in the hot-pressing of undoped and doped $\mathrm{BaTiO}_{3}$ of high purity is around unity and is consistent with earlier work. The grain size exponent $m$ is close to 3 and is different from that obtained in the earlier study, where a densification mechanism of grain boundary sliding in the presence of a viscous boundary phase was believed to be active. The present result indicates grain boundary diffusion control, the difference arising from differences in the hot-pressing temperature, atmosphere, and in the powder quality involved.

No significant influence of donor dopants is observed on the densification of $\mathrm{BaTiO}_{3}$ during hotpressing until the very late stages of sintering.

\section{References}

1. R. J. BRANDMAYR, A, E. BROWN, S. DIVITA and R. J. FISCHER, US Patent 2990602 (1961).

2. A. BROWN and R. FISHER, USA SRDL Technical Report 2196 (1961).

3. R. J. BRANDMAYR, A. E. BROWN and A. M. DUN LAP, USA ECOM Technical Report 2614 (1965).

4. R. C. Devries, J. Amer. Ceram. Soc. 43 (1960) 226
5. K. OKAZAKI and K. TAKAHASHI, J. Phys. Soc. Jpn 28 (Suppl.) (1970) 328.

6. H. C. GRAHAM, N. M. TALLEN and K. S. MAZDIYASNI, J. Amer. Ceram. Soc. 54 (197I) 548.

7. N. C. SHARMA and E. R. McCARTNEY, J. Aust. Ceram. Soc. 10 (1974) 16.

8. H. MOSTAGHACI, PhD thesis, University of Leeds (1982).

9. B. E. WALKER, R. W. RICE, R. C. POHANKA and J. R. S. SPA Nn, Amer. Ceram. Soc. Bull. 55 (1976) 274.

10. A. J. BELL, PhD thesis, University of Leeds (1984).

11. M. F. YAN, Mater. Sci. Eng. 48 (1981) 53.

12. D. HENNINGS, R. JANSSEN and P. J. L. REYNEN, J. Amer. Ceram. Soc. 70 (1987) 23.

13. R. W. DAVIDGE, "Mechanical Behaviour of Ceramics", (Cambridge University Press, 1979) p. 73.

14. W. R. CANNON and T. G. LANGDON, J. Mater. Sci. 18 (1983) 1.

15. H. MOSTAGHACI and R. J. BROOK, Br. Ceram. Trans. J. 84 (1985) 203.

16. L. A. XUE, F. L. RILEY and R. J. BROOK, ibid. 85 (1986) 47.

17. A. L. XUE, PhD thesis, University of Leeds (1987).

18. R. J. WESTON and T. G. CARRUTHERS, Proc. Br. Ceram. Soc. 22 (1973) 197.

19. R. L. COBLE, J. Appl. Phys. 41 (1970) 4798.

20. R. J. BROOK, E. GILBERT, D. HIND and J. VIEIRA, in "Sintering-Theory and Practice", edited by D. Kolar, S. Pejovnik and M. M. Ristic, Materials Science Monographs Vol. 74 (Elsevier, Amsterdam, 1982) pp. 585-590.

21. H. M. O'BRYAN and J. THOMSON Ji. J. Amer. Ceram. Soc. 57 (1974) 522.

22. A. GARCIA-verduCH and R. Linduer, Arkiv Kemi 5 (1953) 313.

23. H. U. ANDERSon, J, Amer. Ceram. Soc. 48 (1965) 118.

24. Y. enomoto and A. YAMAJi, Amer. Ceram. Soc. Bull. 60 (1981) 566.

25. F F. LANGE, J. Amer. Ceram. Soc. 67 (1984) 83.

26. T. J. CARBONE and J. S. REED, Amer. Ceram. Soc. Bull. 58 (1979) 512.

Received 16 May

and accepted 14 July 1988 